\title{
\$ Five Predatory Mega-Journals: A Review
}

British Journal of Science Composite Score: International Journal of Current Research Composite Score:

International Journal of Science and Advanced Technology (IJSAT) Composite Score: International Journal of Sciences (IJSciences) Composite Score:

World Journal of Science and Technology Composite Score:
Reviewed by: Jeffrey Beall, MA, MSLS

Auraria Library

University of Colorado Denver 1100 Lawrence St.

Denver, Colorado, 80204 <jeffrey.beall@ucdenver.edu>

\section{Abstract}

Mega-journals such as PLOS One are an emerging and successful model of scholarly Open Access publishing. Unfortunately, some new, questionable journals have appeared that are copying the megajournal model. This review covers the five predatory mega-journals British Journal of Science, International Journal of Current Research, International Journal of Science and Advanced Technology (IJSAT), International Journal of Sciences (IJSciences), and World Journal of Science and Technology. Each of these journals has a broad coverage that allows them to accept a greater number of articles than journals with a narrow scope. This broad coverage means that, with minimal effort and a single Web site, the journal owners are easily able to attract a substantial amount of author fees.

\section{Pricing Options}

Each of the five journals is Open Access, so there is no charge to readers. Authors, on the other hand, are charged an article processing fee
(APC) upon acceptance of a manuscript. The prices listed here are the APCs for these five journals:

Article processing fee: British Journal of Science $£ 150$

Article processing fee: International Journal of Current Research: Not listed. The site says, "For fee contact editor or publisher."

Article processing fee: International Journal of Science and Advanced Technology (IJSAT): \$150

Article processing fee: International Journal of Sciences (IJSciences): $\$ 150$

Article processing fee: World Journal of Science and Technology: 2,000 rupees for authors from India or \$200 for authors from all other countries.

\section{Product Description}

This review covers five independent mega-journals, each of which uses the gold (author-pays) model of Open Access publishing. Inde-

\section{"At a Glance" Comparative Review Scores}

The maximum number of stars in each category is 5 .

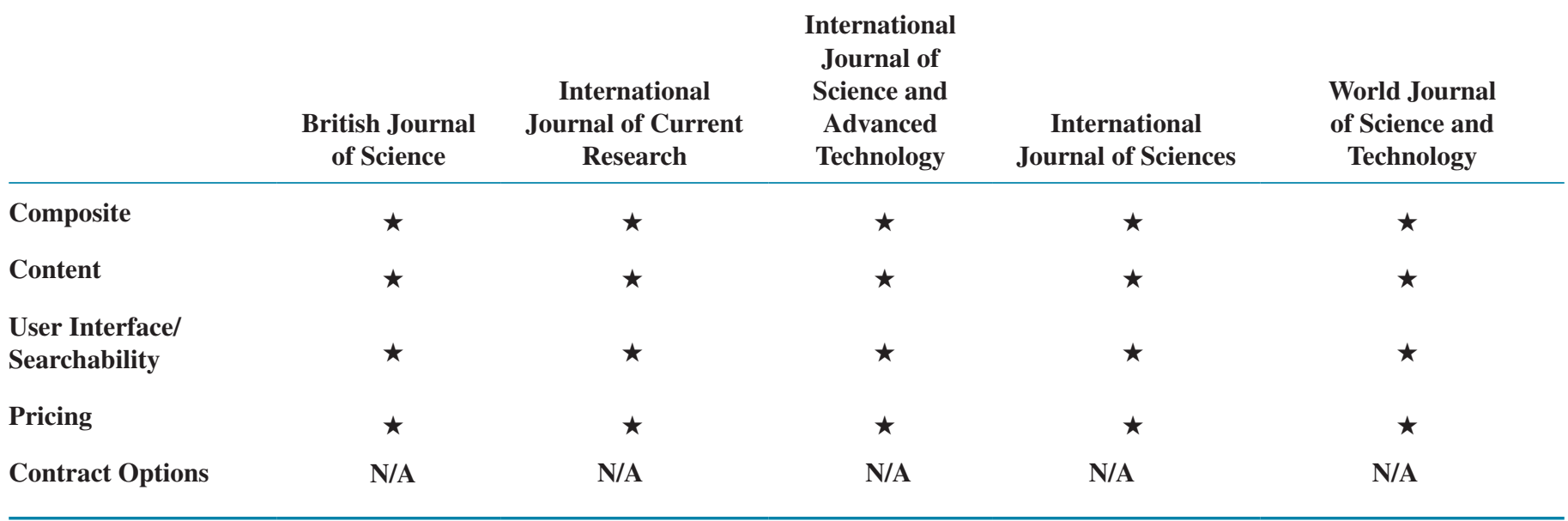


pendent journals do not publish under the sponsorship of any publisher; they are stand-alone journals. The five journals are British Journal of Science, International Journal of Current Research, International Journal of Science and Advanced Technology (IJSAT), International Journal of Sciences (IJSciences), and World Journal of Science and Technology. Each of these journals copies the mega-journal model pioneered by PLOS ONE. That is, they have a broad scope, they perform a light peer review, and they try to accept as many articles as possible. Unlike PLOS ONE, however, predatory mega-journals frequently perform no peer-review at all, despite claiming to do so.

Up until about 2011, few commercial Open Access journals published as independent journals. Most OA journals were parts of fleets, often large fleets, established by Open Access publishers. Mega-journals like the ones described here offer their owners several advantages over publishing operations with fleets of journals. They are easier and cheaper to operate because they have a single workflow and editorial board, and the high number of articles they publish makes them appear more successful, which in turn attracts more articles. Their broad scope invites papers from all areas of science, engineering, and technology, leading to increased income for the journals' owners. In a sense, these mega-journals operate sort of like online repositories rather than journals, for they accept almost everything submitted and add little value to the content they archive.

\section{BRITISH JOURNAL OF SCIENCE}

A true vanity press, this journal is anything but British. It has been publishing since September 2011. The domain name registration hides the registration address but lists the domain owner as Muhammad Naveed Khalid. The journal's Web page is spare, offering little information. The journal does list an editorial board, but we think it's mostly contrived. For example, the page says, "Editor-in-Chief Howard Longford, University of California," yet a Google search for this information is inconclusive and presents the editorial board page as the top search result.

The articles all bear a copyright statement. We easily found numerous instances of plagiarism among them. In fact, we found one article entitled "Expert Task Force Consideration of Confidentiality, Effect Sizes, and Computerized Adaptive Testing at NCES" that is an exact copy of a report published two years earlier. In the duplicated article, the names and affiliations have been changed. The copyediting in the articles is very poor. The journal uses no standard numbers, lists very few policies, and lacks a strategy for digital preservation. This journal is a rich treasury of author misconduct and unethical publishing practices.

\section{INTERNATIONAL JOURNAL OF CURRENT RESEARCH}

This journal does not indicate its headquarters location, but a domain name search reveals a Pondicherry, India registration address. The journal is monthly and began publishing in January 2010. The site's crowded main page includes two cute baby pictures, and a prominent link to PayPal. There is also an image indicating that the journal's 2011 impact factor was 1.125 , which is false, for the journal has no official impact factor.

The articles bear a copyright statement, despite the journal's claim that it is Open Access, and authors are required to sign over copyright to the journal. The author guidelines are copied from another publisher, a common practice among predatory journals. In fact, if you complete a Google search of a phrase from the guidelines, you get numerous hits, and many are from predatory publishers that have copied the same guidelines. It was easy for me to find instances of plagiarism in the articles. One article entitled "Architecture in Samani Ages" is plagiarized from Wikipedia; indeed, even the first line of the article's abstract is boldly copied from that source.

Most of the journal's authors are from Asia and Africa. The journal's managers all use e-mail addresses that end in yahoo.com. The members of the editorial board are listed along with their affiliations and specialties, and the editor in chief, Dr. Jonas Contiero, is from Brazil. The Web site has dead image and page links and is somewhat difficult to navigate. An example of one of the journal's spam email solicitations was forwarded to us, and it states, "Our objective is to inform authors of the decision on their manuscript(s) within $24 \mathrm{~h}$ of submission." This likely means that no real peer review is carried out, so that the journal is essentially a vanity press.

\section{INTERNATIONAL JOURNAL OF SCIENCE AND ADVANCED TECHNOLOGY (IJSAT)}

This journal has the ungrammatical tagline "Blindly Peer-reviewed Research Publishing Journal" displayed prominently at the top of its main page. The "Contact us" page only has a Web form and an e-mail address and does not reveal the journal's headquarters location. However, on the site's Indexing \& Archiving page, it says, "IJSAT Publishers Dhaka 1219, Bangladesh.”

The site's main page proudly displays a QR code, but a scan of the code absurdly brings the user back to the same page. The code is just for show. The bottom of the main page displays an icon for the Creative Commons Attribution-NoDerivs 3.0 license, but a copyright statement also appears nearby, perhaps reflecting the journal's confusion about copyright. Individual articles lack any licensing information. The journal publishes monthly and began with its first issue in March 2011.

The journal has an editorial board listed and also a reviewer panel. The editorial board lists 11 men, yet only one has affiliation listed. The others follow the pattern of the fifth name on the list: "Prof. Dr. T Harris, United States of America." The reviewer panel is larger and lists institutional affiliations. Authors are required to sign over copyright to the publisher when a paper is accepted. The journal's "Instructions for authors" is only a few sentences long, and it includes this sentence, "We accept extended version of papers previously published in conferences and/or journals." So, it appears that the journal has no problem with duplicate publication. We observed instances of self-plagiarism and plagiarism among the articles. Finally, the journal does have an ISSN but does not use any other standard numbers.

\section{INTERNATIONAL JOURNAL OF SCIENCES (IJSCIENCES)}

The most prominent visual feature of this journal's main page is the large, ornamental, cursive font that appears up and down the page. The journal purports to be headquartered in Manchester, England, but we cannot confirm this because data from the domain name registration is blocked. The journal published its first issue in October 2012 and appears to be a monthly.

The journal has both an editorial board and a reviewer board, but the site does not explain the difference between the two. To serve on the reviewer board, one must have already published one paper in the journal, and to serve on the editorial board, two papers. We've not seen this requirement before, and it appears to be a strategy to get more author fees. The first listing on the editorial board is this: "Dr. Abraham (Cheif [sic] Editor) The University of Manchester, UK." 


\section{British Journal of Science Review Scores Composite: $\star$}

The maximum number of stars in each category is 5 .

\section{Content:}

Complete rubbish. The site includes pirated content including plagiarism.

User Interface/Searchability:

The vacant Web site leaves many questions unanswered.

Pricing:

The price is low, but the cost of having your research appear here will be high
Contract Options:
N/A.

\section{International Journal of Current Research Review Scores Composite: $\star$}

The maximum number of stars in each category is 5 .

\section{Content:}

If you can't find a publisher to publish your work, visit this journal; it will accept anything.

User Interface/Searchability:

A crowded Web site, plus it's difficult to navigate to the journal's early issues.

\section{Pricing:}

The article processing fee is not listed on the Web site, so we fear the journal lacks a fair pricing scheme.
Contract Options:
N/A

\section{International Journal of Science and Advanced Technology (IJSAT) Review Scores Composite: $\star$}

The maximum number of stars in each category is 5 .

\section{Content:}

The journal's tagline is "blindly peer-reviewed," and we agree that no reviewer likely examined any of the site's content.

User Interface/Searchability:

Confusing, with slow servers, this site has elements that scroll and blink. It's designed around the needs of its paying customers, the authors.

Pricing:

Any cost for publishing here is too high.

Contract Options: 


\section{International Journal of Sciences (IJSciences) Review Scores Composite: $\star$}

The maximum number of stars in each category is 5 .

\section{Content:}

Low-quality articles that exist only for the purpose of puffing up CVs.

\section{User Interface/Searchability:}

A minimalist Web site that overuses the decorative font, this site was probably created in one sitting.

\section{Pricing:}

The lowest listed price among the journals treated here, but still too high a price given the low overall quality of the journal.
Contract Options:
N/A

\section{World Journal of Science and Technology Review Scores Composite: $\star$}

The maximum number of stars in each category is 5 .

\section{Content:}

More of a repository than a coherent journal, this site specializes in publishing anything.

\section{User Interface/Searchability:}

The site does offer a search page, but we're not sure why anyone would want to search the site's third-tier content.

\section{Pricing:}

Authors have the choice of paying 2,000 rupees or $\$ 200$; we recommend none of the above.

\section{Contract Options: $\quad$ N/A}

This may be a fake name, for we were unable to find any information about Dr. Abraham using Google.

At the bottom of the main page there are these statements: "Copyright (c) 2012 ijSciences.com. All rights reserved. This work is licensed under a Creative Commons Attribution 3.0 License." These statements are contradictory, of course, and they demonstrate the journal owner's naiveté with licensing. Overall, the site is spare and includes very little information. There are logos placed at the bottom of each of the site's pages -- Google Scholar, DOAJ, SSRN, and three others, an attempt to steal some of the organizations' brand value and make the journal look more legitimate.

\section{WORLD JOURNAL OF SCIENCE AND TECHNOLOGY}

This journal states that it is sponsored by the Khajure Research Foundation and Development Society, based in Karnataka, India. A majority of the journal's editorial board hails from India, despite its claim to being a "world journal." The journal generally publishes monthly, with the first issue appearing in early 2011.

Authors are asked to sign over copyright, and the journal's Web pages bear copyright statements, yet the article PDFs lack any license information, and there is no mention of Creative Commons licenses anywhere on the Web site. I had no trouble finding examples of plagiarism in the articles. The plagiarism is salient because the articles are poorly copyedited. The plagiarized text stands out because it is more grammatical and readable than the authors' original text. The journal does have a section of its Web site called "Policy on plagiarism," and not surprisingly, the content of the page is copied from other Web sites.

Many of the individual articles are rather short; two- or three-page articles are common, an indication that some are using the journal as a vanity press just to get a quick publication. The journal claims to be indexed in EBSCOhost and Chemical Abstracts, among several 
other indexes. We checked EBSCO and Chem Abstracts and found the claims false.

The journal does not mention any digital preservation strategies. It has an ISSN but uses no other standard numbers. Like many predatory publishers, this journal uses professional images taken from other Web sites to adorn its pages.

\section{Critical Evaluation}

\section{BRITISH JOURNAL OF SCIENCE}

This journal shamelessly invents and includes false information on its Web site, such as invented names on its editorial board, just to attract author fees. Another function of this journal may be to help earn "foreign" publications for authors in Asia and Africa, for in many countries authors receive greater academic credit for foreign rather than national publications. So the journal's title is no accident; it is meant to convince readers that it's a truly British journal, when it is really just a vanity press. This journal commits publishing misconduct of the worst kind-it steals articles from other Web sites, changing the titles and authors and republishing them under its own banner. This is likely done to make the journal appear legitimate to potential authors. We recommend that researchers submit no manuscripts to this journal.

\section{Contact Information}

\section{British Journal of Science}

ISSN: 2047-3745

E-mail: <office.sjournal@gmail.com>

URL: <http://www.ajournal.co.uk/index.htm>

\section{International Journal of Current Research}

ISSN: 0975-833X

E-mail: <dr.mani_2011@yahoo.com>

URL: <http://www.journalcra.com/>

\section{International Journal of Science and Advanced Technology (IJSAT) \\ ISSN: 2221-8386 \\ Dhaka-1219, Bangladesh \\ E-mail: <editor@ijsat.com> \\ URL: <http://www.ijsat.com/index.php>}

\section{International Journal of Sciences (IJSciences)}

ISSN: 2305-3925

Alkhaer Publications

31 Smedley Lane Cheetamhill Road

Manchester M8 8XG, England

E-mail: <info@ijsciences.com>

URL: <http://www.ijsciences.com/>

\section{World Journal of Science and Technology}

\section{ISSN: 2231-2587}

c/o KRFD Society

Kufar Toad Mohalla

Humnabad 585330

Karnataka, India

E-mail: <managingeditor@worldjournalofscience.com> URL: <http://worldjournalofscience.com/index.php/wjst/>

\section{INTERNATIONAL JOURNAL OF CURRENT RESEARCH}

This journal is also a vanity press. Its busy front page is designed to appeal to potential authors and to get them to submit papers and then pay the required fee for publication. The site is a parade of lies, as exemplified by its listing an impact factor on its front page when it really has none. This site serves as an example of a formulaic predatory Open Access publisher. Many across Asia want to cash in on the gold rush, that is, the gold Open Access publishing industry. It's easy money; all you need is to set up one Web site and come up with a journal title, a day's work. After spamming thousands of scholars, a few manuscripts start to trickle in, and you're in business. The ongoing work is easy, takes little time, and provides a steady income. Also, the publishers save money by ignoring digital preservation, making all their content subject to being lost in a hardware failure. Do not submit any papers to this journal.

\section{INTERNATIONAL JOURNAL OF SCIENCE AND ADVANCED TECHNOLOGY (IJSAT)}

This Bangladeshi journal is another example of a journal that just wants your money. Its crowded front page is designed to appeal to authors and to get them to submit their papers. The journal knows that it must include licensing information to look legitimate, but it ends up listing contradictory information by using CC licenses and the statement "all rights reserved." The obvious occurrence of plagiarism and self-plagiarism evident in the journal's articles confirms the publication's vanity press function. Authors can revise their earlier works for a quick addition to their $\mathrm{CV}$, fulfilling those annoying academic requirements. Never has academic misconduct been so easy. Sites like this one function as enablers of author misconduct. We strongly recommend against sending any papers to this journal.

\section{INTERNATIONAL JOURNAL OF SCIENCES (IJSCIENCES)}

This site must have taken little time to set up, for it is spare and lacks information that all journals should provide, such as retraction policy, review process, and digital preservation information. It uses a decorative font in an attempt to look sophisticated, but the appearance is really silly and unprofessional. Like the previous journal, this one is confused about the difference between CC BY and "all rights reserved." The journal uses images likely lifted from other sites to decorate its main page, further evidence of its confusion over Open Access. If you want to buy your way onto an editorial board, this journal is the place to do it, for after paying for the required number of author fees, one's name will be added to the list. We think the work of the reviewers is little or none, so some will find this a great way to enhance their CV. Honest researchers, on the other hand, should not send any submissions to this journal.

\section{WORLD JOURNAL OF SCIENCE AND TECHNOLOGY}

This would truly be a world journal if the world were limited to the Karnataka, India metropolitan area. Most all the authors and editorial board members are from south Asia. It's lamentable that such a great journal title has been used by such a poorly-managed operation. This is a vanity press, a money-making operation for its owners. Never has the collusion between predatory publishers and unethical authors been so easy to carry out. That collusion is really what's for sale here, with this journal and the others. This journal is a formulaic Open Access publisher, set up using a now established, predatory Open Access publishing model. Its goal is to earn author fees, living for the moment only, an affront to the established system of scholarly communication. We recommend that authors seeking a place to publish their 
research seek a venue other than this one, indeed other than all the journals described here.

\section{Contract Provisions}

Because the content of all the journals is Open Access, contracts are not applicable to readers. Authors are the true customers of Open Access journals, so this section lists each journal's requirements regarding copyright transfer.

British Journal of Science: No copyright transfer requirement is indicated.

International Journal of Current Research: Authors must agree that when an article is accepted for publication copyright transfers to the journal.

International Journal of Science and Advanced Technology (IJSAT): Authors must sign over copyright to the journal.

International Journal of Sciences (IJSciences): No copyright transfer requirement is indicated.
World Journal of Science and Technology: Authors must sign a copyright transfer agreement when a paper is accepted.

\section{Authentication}

No authentication is required because all the journals' content is Open Access. In some cases, authors submitting papers are required to register and sign in for an account with the journal.

\section{About the Author}

Jeffrey Beall is Scholarly Initiatives Librarian and Associate Professor at Auraria Library on the downtown Denver campus of the University of Colorado Denver. An academic librarian for 23 years, his research and writing have been featured in the Journal of Academic Librarianship, Cataloging \& Classification Quarterly, College \& Research Libraries and Nature. His blog, Scholarly Open Access $<\mathrm{http}$ ///scholarlyoa.com>, lists predatory publishers and journals and discusses issues surrounding Open Access publishing, publishing ethics, and author misconduct.

\section{Available from Ingram, Blackwell, Baker and Taylor, and most other major distributors}

\section{MLA's Essential Resource for Libraries}

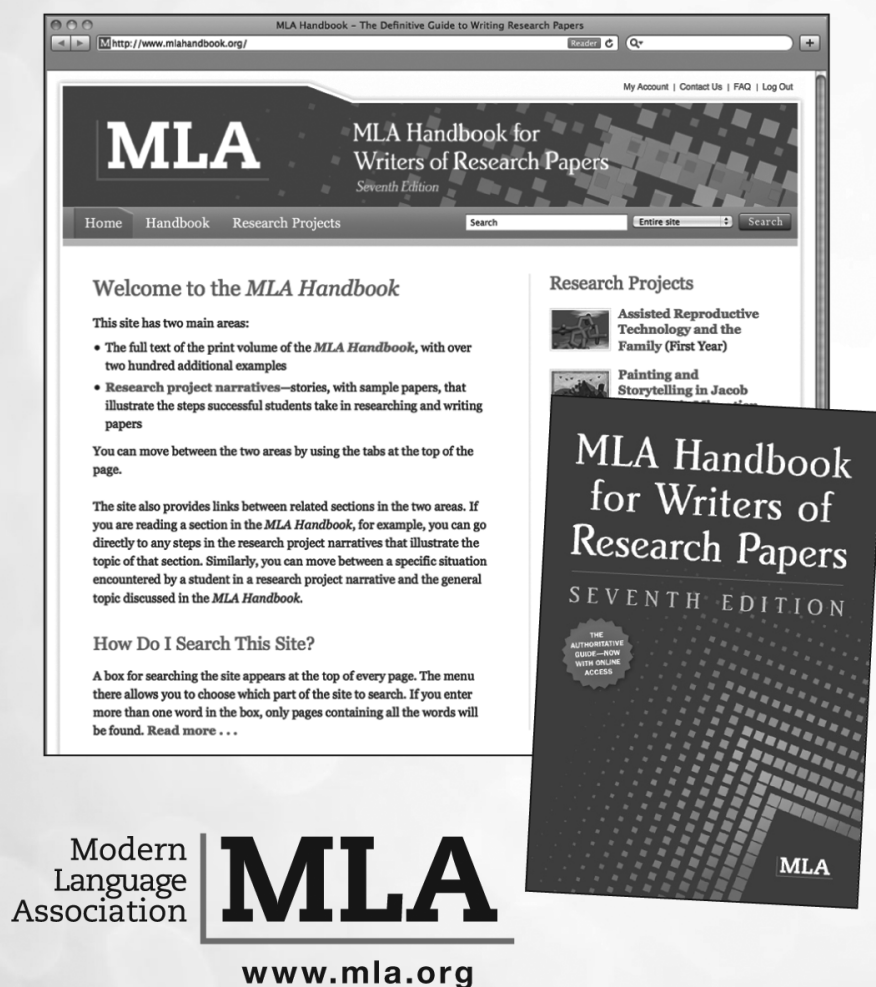

\section{Available in Print and Online}

Widely adopted by universities, colleges, and secondary schools, the MLA Handbook gives step-by-step advice on every aspect of writing research papers, from selecting a topic to submitting the completed paper.

Buy access to the MLA Handbook online at

\section{www.mlahandbook.org}

and start using it today. A print copy will be mailed to you.

\section{Recipient of Choice Award for Outstanding Academic Title}

Searchable Web site features

- the full text of the MLA Handbook

- over two hundred additional examples

- research project narratives, with sample papers

- continuous access throughout the life of the seventh edition of the MLA Handbook

xxii \& $292 \mathrm{pp} . \quad$ LARGE-PRINT EDITION

Paper 978-1-60329-024-1 $\$ 22.00$ Paper 978-1-60329-025-8 $\$ 30.00$ 